\title{
Association of White Blood Cell Count and Clustered Components of Metabolic Syndrome in Japanese Men
}

\author{
Nobue Nagasawa, MS*†; Koji Tamakoshi, MD*; Hiroshi Yatsuya, MD*; Yoko Hori, PhD*; \\ Miyuki Ishikawa, ME*; Chiyoe Murata, MPH*; Huiming Zhang, MD*; \\ Keiko Wada, MD*; Rei Otsuka, MS*; Tomoko Mabuchi, MS*; \\ Takaaki Kondo, MD**; Hideaki Toyoshima, MD*
}

\begin{abstract}
Background The role of inflammation in the genesis of cardiovascular disease has attracted attention and in the present study the association among metabolic syndrome (MS), white blood cell (WBC) count, and insulin concentration was investigated.

Methods and Results A cross-sectional study of 3,594 Japanese men aged 34-69 years evaluated the MS components (high blood pressure, hypo-high density lipoprotein (HDL)-cholesterolemia, hypertriglyceridemia, hyperglycemia), as defined by the criteria given in the Third Report of the National Cholesterol Education Program Expert Panel on Detection Evaluation, and Treatment of High Blood Cholesterol in Adults, except for obesity [body mass index (BMI) $\geq 25 \mathrm{~kg} / \mathrm{m}^{2}$ ]. WBC count had a positive correlation with BMI, blood pressure, triglyceride, glucose and insulin, and a negative correlation with HDL-cholesterol. The multi-adjusted means of WBC count and insulin concentration were significantly higher in MS subjects defined as having 3 or more of the components than in non-MS subjects with no more than 2 components. Both means also increased with the number of MS components $(\mathrm{p}<0.001$ for trend). In the multiple linear regression analysis, BMI, HDL-cholesterol, systolic blood pressure, glucose and triglyceride had a significant and independent association with WBC count, but the insulin concentration did not.
\end{abstract}

Conclusions The cluster of MS components based on insulin resistance may cause low-grade inflammation. (Circ J 2004; 68: 892-897)

Key Words: Cardiovascular disease risk factor; Japanese men; Low-grade inflammation; Metabolic syndrome; White blood cell

$\mathbf{R}$ ecent epidemiological studies have reported an association between cardiovascular disease (CVD) risk factors and inflammation, ${ }^{1-3}$ and the latter has been recently identified as an independent risk factor for CVD-4-6 However, its role in the genesis of CVD remains to be elucidated. The white blood cell (WBC) count is an objective marker of acute infection, tissue damage, and other inflammatory conditions. An increase in the count is closely correlated with advanced atherosclerosis? and the incidence and mortality rate of CVD?-13 Therefore, the WBC count is a CVD risk factor, together with fibrinogen and C-reactive protein (CRP). Because it is included in the blood tests for routine health examinations, the WBC count may be a useful indicator of CVD and the onset of atherosclerosis.

(Received May 24, 2004; revised manuscript received July 6, 2004; accepted July 9, 2004)

*Department of Public Health/Health Information Dynamics, Field of Social Life Science, Program in Health and Community Medicine, Nagoya University Graduate School of Medicine, Nagoya, **Department of Medical Technology, Nagoya University School of Health Science, Nagoya and Department of Food and Nutrition, Faculty of Human Life, Jumonji University, Saitama, Japan

Mailing address: Hideaki Toyoshima, MD, Department of Public Health, Nagoya University Graduate School of Medicine, 65 Tsurumaicho, Showa-ku, Nagoya 466-8550, Japan. E-mail: toyosima@med. nagoya-u.ac.jp
Metabolic syndrome (MS), which comprises various metabolic disorders that are linked on the basis of insulin resistance, is a known risk factor for CVD!4-16 Therefore, investigation of the mechanism of the elevated WBC count requires an understanding of the association between the count and each of the MS components related to CVD. Over the years, researchers have included disorders of insulin resistance, obesity, high blood pressure (BP), glucose intolerance, dyslipidemia, hyperuricemia, coagulation disorders, and inflammation in the definition of $\mathrm{MS}^{17}$ but recently a definition of the MS components was published in the Third Report of the National Cholesterol Education Program (NCEP) Expert Panel on Detection, Evaluation and Treatment of High Blood Cholesterol in Adults (ATP III) $)^{18}$ In the present study, we studied the association among the normal range of WBC count, insulin concentration, and the clustering of MS components as defined by the ATP III, using data for Japanese men recorded at annual employees' health examinations.

\section{Methods}

\section{Subjects}

We conducted a cross-sectional study of a population of 3,716 Japanese men aged 34-69 years who participated in annual health examinations at 2 workplaces in Nagoya, Japan, in 1997. Participants completed a self-reported 
questionnaire including medical history, medication use, smoking status, drinking status, and physical activity, underwent a physical examination including height, weight, and blood pressure measured sitting after $5 \mathrm{~min}$ rest, and provided overnight fasting blood samples.

Smoking status was classified into 4 levels (never, past and current smoker of 1-24 or $\geq 25$ cigarettes/day). Alcohol drinking status was first assessed by the number of drinking days per week (none, 1-3, 4-6 or daily), then, for those who drank, it was further categorized into 3 levels (light, moderate, and heavy) by weekly consumption obtained as the daily alcohol consumption multiplied by the number of days of drinking per week. Each level approximately corresponded to less than $23,23-46$, and $\geq 46$ grams of ethanol consumption per day, respectively.

We excluded individuals with WBC counts of $\geq 10,000$ cells $\mu 1 \quad(n=122)$, indicating clinically relevant inflammatory conditions. Those with a history of chronic disease such as CVD or stroke were not excluded. Finally, the current analysis was restricted to 3,594 men with complete data on all the components of the MS and the WBC count. All subjects in the study gave their informed consent for the use of personal information for analysis. The Ethics Committee of Nagoya University Graduate School of Medicine, Nagoya, Japan, approved the study protocol.

\section{Biochemical Analyses}

Venous blood samples were drawn from the subjects after an $8 \mathrm{~h}$ or overnight fast and stored at $-80^{\circ} \mathrm{C}$ until assay. Triglycerides (TG) were determined enzymatically; high density lipoprotein-cholesterol (HDL-C) was measured by the phosphotungstate method; glucose was enzymatically determined by the hexokinase method; insulin concentration was measured by immunoradiometric assay; and the WBC count was determined by automated particle counters within $24 \mathrm{~h}$ after venipuncture in a commercial laboratory.
Table 1 Characteristics of the 3,594 Male Subjects

\begin{tabular}{|c|c|c|}
\hline & No. of subjects & $(\%)$ \\
\hline \multicolumn{3}{|l|}{ Age (years) } \\
\hline 34-39 & 246 & 6.8 \\
\hline $40-49$ & 1,146 & 31.9 \\
\hline $50-59$ & 2,092 & 58.2 \\
\hline $60-69$ & 110 & 3.1 \\
\hline Mean $\pm S D$ & $50.4 \pm 6.6$ & \\
\hline \multicolumn{3}{|l|}{ Smoking status } \\
\hline None & 1,274 & 35.4 \\
\hline Past & 605 & 16.8 \\
\hline Current 1-24 cigarettes/day & 1,127 & 31.4 \\
\hline Current $\geq 25$ cigarettes/day & 588 & 16.4 \\
\hline \multicolumn{3}{|l|}{ Drinking status } \\
\hline None & 955 & 26.6 \\
\hline Little & 820 & 22.8 \\
\hline Moderate & 907 & 25.2 \\
\hline Heavy & 912 & 25.4 \\
\hline \multicolumn{3}{|l|}{ Medication } \\
\hline $\begin{array}{l}\text { Hypercholesterolemia } \\
\quad \text { and/or hypertriglyceridemia }\end{array}$ & 91 & 2.5 \\
\hline Diabetes & 111 & 3.1 \\
\hline Hypertension & 330 & 9.2 \\
\hline Cardiovascular disease & 75 & 2.1 \\
\hline Stroke & 5 & 0.1 \\
\hline \multicolumn{3}{|l|}{ Medical history } \\
\hline Stroke & 23 & 0.6 \\
\hline Myocardial infarction & 30 & 0.8 \\
\hline Cancer & 42 & 1.2 \\
\hline Liver disease & 208 & 5.8 \\
\hline Asthma & 99 & 2.8 \\
\hline Atopy & 97 & 2.7 \\
\hline
\end{tabular}

\section{Statistical Analyses}

The characteristics of the MS components except obesity were defined by the following cutoff limits as detailed in the ATP III report: ${ }^{18}$ (i) high BP: systolic (SBP) $\geq 130 \mathrm{mmHg}$ and/or diastolic (DBP) $\geq 85 \mathrm{mmHg}$ and/or medication for hypertension; (ii) hypo-HDL-cholesterolemia: HDL-C $<40 \mathrm{mg} / \mathrm{dl}$; hypertriglyceridemia: $\mathrm{TG} \geq 150 \mathrm{mg} / \mathrm{dl}$ and/or

Table 2 Anthropometric and Biochemical Variables of the 3,594 Subjects

\begin{tabular}{lcccc}
\hline \hline Variable & Mean $\pm S D$ & Median & 25th percentile & 75th percentile \\
\hline White blood cell count $($ cells $\mathbf{1} \mathrm{l})$ & $5,981 \pm 1,395$ & 5,800 & 5,000 & 6,900 \\
Body mass index $\left(\mathrm{kg} / \mathrm{m}^{2}\right)$ & $22.9 \pm 2.7$ & 22.9 & 21.0 & 24.7 \\
Systolic blood pressure $(\mathrm{mmHg})$ & $129.0 \pm 18.5$ & 127.0 & 116.0 & 141.0 \\
Diastolic blood pressure $(\mathrm{mmHg})$ & $80.0 \pm 11.9$ & 79.0 & 71.0 & 87.0 \\
HDL-cholesterol $(\mathrm{mg} / \mathrm{dl})$ & $55.0 \pm 14.0$ & 53.0 & 45.0 & 63.0 \\
Triglyceride $(\mathrm{mg} / \mathrm{dl})$ & $133.2 \pm 92.5$ & 110.0 & 78.0 & 157.0 \\
Fasting plasma glucose $(\mathrm{mg} / \mathrm{dl})$ & $99.7 \pm 21.4$ & 96.0 & 89.0 & 104.0 \\
Fasting plasma insulin $(\mathrm{\mu} \mathrm{U} / \mathrm{ml})$ & $5.6 \pm 4.9$ & 5.0 & 3.0 & 7.0 \\
\hline
\end{tabular}

Table 3 Pearson's Correlation Coefficients (r) Between Each of the Metabolic Syndrome Components and the Respective WBC Count and Fasting Insulin

\begin{tabular}{|c|c|c|c|c|}
\hline \multirow{2}{*}{ Variable } & \multicolumn{2}{|c|}{ WBC count } & \multicolumn{2}{|c|}{ Fasting insulin } \\
\hline & Pearson, $r$ & $p$ value & Pearson, $r$ & $p$ value \\
\hline Age (years) & 0.06 & 0.001 & -0.05 & 0.007 \\
\hline Body mass index $\left(\mathrm{kg} / \mathrm{m}^{2}\right)$ & 0.12 & $<0.001$ & 0.53 & $<0.001$ \\
\hline Systolic blood pressure ( $\mathrm{mmHg}$ ) & 0.06 & $<0.001$ & 0.26 & $<0.001$ \\
\hline Diastolic blood pressure ( $\mathrm{mmHg}$ ) & 0.05 & $<0.001$ & 0.24 & $<0.001$ \\
\hline HDL-cholesterol $(\mathrm{mg} / \mathrm{dl})$ & -0.24 & $<0.001$ & -0.31 & $<0.001$ \\
\hline Log-transformed triglyceride $(\mathrm{mg} / \mathrm{dl})$ & 0.23 & $<0.001$ & 0.39 & $<0.001$ \\
\hline Fasting plasma glucose $(\mathrm{mg} / \mathrm{dl})$ & 0.06 & $<0.001$ & 0.20 & $<0.001$ \\
\hline Log-transformed fasting insulin $(\mu \mathrm{U} / \mathrm{ml})$ & 0.11 & $<0.001$ & - & - \\
\hline WBC count (cells隹l) & - & - & 0.11 & $<0.001$ \\
\hline
\end{tabular}


Table 4 Mean WBC Count Adjusted for Categorized Components of Metabolic Syndrome Among 3,594 Japanese Men Aged 34-69 Years (WBC Count $<\mathbf{1 0 , 0 0 0}$ cells $/ \mathrm{l}$ )

\begin{tabular}{|c|c|c|c|c|c|}
\hline Components of metabolic syndrome & $n(\%)$ & $\begin{array}{l}\text { Age-adjusted means of } \\
W B C \text { count } *(95 \% \text { Cl })\end{array}$ & $p$ value ${ }^{\dagger}$ & $\begin{array}{l}\text { Multi-adjusted means of } \\
\text { WBC count } * *(95 \% \mathrm{Cl})\end{array}$ & $p$ value ${ }^{c}$ \\
\hline \multicolumn{6}{|l|}{ Obesity } \\
\hline$<25 \mathrm{~kg} / \mathrm{m}^{2}$ & $2,791(77.7)$ & $5,912(5,861-5,964)$ & & $5,905(5,857-5,952)$ & \\
\hline$\geq 25 \mathrm{~kg} / \mathrm{m}^{2}$ & $803(22.3)$ & $6,218(6,122-6,314)$ & $<0.001$ & $6,245(6,156-6,335)$ & $<0.001$ \\
\hline \multicolumn{6}{|l|}{ High blood pressure } \\
\hline $\mathrm{SBP}<130 \mathrm{mmHg}$ and $\mathrm{DBP}<85 \mathrm{mmHg}$ & $1,846(51.4)$ & $5,943(5,879-6,007)$ & & $5,876(5,816-5,936)$ & \\
\hline $\begin{array}{l}S B P \geq 130 \mathrm{mmHg} \text { or } \mathrm{DBP} \geq 85 \mathrm{mmHg} \text { or medication } \\
\text { for hypertension }\end{array}$ & $1,748(48.6)$ & $6,021(5,955-6,087)$ & 0.101 & $6,091(6,029-6,153)$ & $<0.001$ \\
\hline \multicolumn{6}{|l|}{ Hypo-HDL-cholesterolemia } \\
\hline$\geq 40 \mathrm{mg} / \mathrm{dl}$ & $3,205(89.2)$ & $5,917(5,869-5,965)$ & & $5,944(5,899-5,988)$ & \\
\hline$<40 \mathrm{mg} / \mathrm{dl}$ & $389(10.8)$ & $6,508(6,370-6,645)$ & $<0.001$ & $6,287(6,155-6,418)$ & $<0.001$ \\
\hline \multicolumn{6}{|l|}{ Hypertriglyceridemia } \\
\hline$<150 \mathrm{mg} / \mathrm{dl}$ & $2,537(70.6)$ & $5,842(5,789-5,896)$ & & $5,867(5,817-5,917)$ & \\
\hline$\geq 150 \mathrm{mg} / \mathrm{dl}$ or medication for dyslipidemia & $1,057(29.4)$ & $6,313(6,230-6,396)$ & $<0.001$ & $6,253(6,176-6,331)$ & $<0.001$ \\
\hline \multicolumn{6}{|l|}{ Hyperglycemia } \\
\hline$<110 \mathrm{mg} / \mathrm{dl}$ & $3,013(83.8)$ & $5,950(5,900-6,000)$ & & $5,947(5,901-5,993)$ & \\
\hline$\geq 110 \mathrm{mg} / \mathrm{dl}$ or medication for diabetes & $581(16.2)$ & $6,139(6,025-6,253)$ & 0.003 & $6,156(6,050-6,262)$ & $<0.001$ \\
\hline
\end{tabular}

*Data are adjusted for age.

**Data are adjusted for age, smoking status, drinking status, medical histories of stroke, myocardial infarction, cancer, liver disease, asthma, and atopy. tDifference in means.

CI, confidence interval; SBP, systolic blood pressure; DBP, diastolic blood pressure.

medication for hyperlipidemia, and (iv) hyperglycemia: fasting plasma glucose $\geq 110 \mathrm{mg} / \mathrm{dl}$ and/or medication for diabetes. For the fifth component of MS, subjects who had a body mass index (BMI), calculated as weight (kilograms) divided by height (meters) squared, of $\geq 25 \mathrm{~kg} / \mathrm{m}^{2}$ were defined as obese according to the criteria recommended by the Japan Society for the Study of Obesity 19 because we could not obtain their waist measurements. Subjects with 3 or more of these components were defined as having MS.

Pearson's correlation coefficients were obtained between the value of each of the MS components and the respective WBC count and plasma insulin concentration. Fasting plasma insulin and TG were skewed and were normalized by logarithmic transformation in all analyses. Mean WBC counts were calculated across the categorized components of MS. All mean values were adjusted for years of age by means of a multiple general linear regression model. Further adjustment was performed with smoking status, drinking status and a medical history of stroke, cardiac infarction, cancer, liver disease, asthma or atopy.

Subjects with different numbers of MS components were grouped into 6 subgroups graded by numbers $0-5$. Means of WBC counts and log-transformed plasma insulin were then calculated for each subgroup by means of a multiple linear regression model, with adjustment for age, smoking status, drinking status, and medical history as described before. After subjects were grouped into those with and without MS, the means of WBC counts and log-transformed plasma insulin were calculated for each by means of a multiple general linear regression model. Multiple linear regression analysis with the WBC count as the dependent variable, and components of MS and confounding factors as the independent variables was used to identify significant predictors for WBC counts.

All statistical analyses were performed with the SPSS statistical package for Windows version 11.0?20 All reported $\mathrm{p}$-values were two-sided, and $\mathrm{p}<0.05$ was considered statistically significant.

\section{Results}

The characteristics of the subjects and distribution of the MS components among the 3,594 Japanese men are shown in Tables 1 and 2. Pearson's correlation coefficients between each of the components of MS and each WBC count and log-transformed plasma insulin are shown in Table 3. There were statistically significant positive correlations $(\mathrm{p}<0.001)$ between the WBC count and age, BMI, SBP, DBP, TG, fasting plasma glucose, and fasting plasma insulin. A negative correlation was found between the WBC count and HDL-C. The WBC count had the strongest correlation with TG $(r=0.23)$ and HDL-C $(r=-0.24)$. The insulin concentration had a statistically significant positive correlation with BMI, SBP, DBP, TG, glucose, and WBC count, and showed a significant negative correlation with age and HDL-C. By far the strongest correlation was observed between the insulin concentration and BMI $(\mathrm{r}=0.53)$.

Table 4 shows the adjusted mean WBC counts for the different groups with respect to the 5 components of MS. The age-adjusted mean WBC counts were significantly higher in obese subjects and those with hypo-HDL-cholesterolemia, hypertriglyceridemia or hyperglycemia than in those without these components, and did not differ between subjects with and without high BP. After further adjustment for smoking status, drinking status, and medical history, the mean WBC counts were still significantly higher in subjects with each of the MS components than in those without $(\mathrm{p}<0.001$ for all).

Only $31.6 \%$ of all subjects were free of all 5 components and $16 \%$ were diagnosed as having MS (Table 5). The multi-adjusted means of insulin concentration and WBC count were significantly higher in MS subjects than in nonMS subjects $(\mathrm{p}<0.001)$. Compared with a multi-adjusted WBC mean of 5,758 cells $\mu 1$ for subjects without any MS components, the means of those with 1,2,3, 4, and 5 components were $5,910,6,136,6,236,6,535$, and 7,269 cells $\mu 1$, respectively, showing a significant increasing trend $(\mathrm{p}<$ 0.001 for trend). The log-transformed insulin concentrations also showed a significant increasing trend, together 
Table 5 Adjusted Means of the WBC Count and Fasting Insulin for Clustered Components of Metabolic Syndrome

\begin{tabular}{crccc}
\hline \hline No. of components* & $n$ & $\%$ & $\begin{array}{c}\text { Multi-adjusted } * * \text { means } \\
\text { of insulin }(95 \% \text { Cl) } * * *\end{array}$ & $\begin{array}{c}\text { Multi-adjusted } * * \text { means } \\
\text { of WBC count }(95 \% \text { Cl) }\end{array}$ \\
\hline 0 & 1,136 & 31.6 & $3.49(3.38-3.60)$ & $5,758(5,683-5,833)$ \\
1 & 1,098 & 30.6 & $4.48(4.35-4.62)$ & $5,910(5,834-5,985)$ \\
2 & 784 & 21.8 & $5.53(5.37-5.75)$ & $6,136(6,047-6,226)$ \\
3 & 408 & 11.4 & $7.17(6.82-7.54)$ & $6,236(6,112-6,360)$ \\
4 & 152 & 4.2 & $8.41(7.77-9.12)$ & $6,535(6,331-6,739)$ \\
5 & 16 & 0.4 & $9.78(7.69-12.55)$ & $7,269(6,642-7,896)$ \\
& & & Trend $p<0.001$ & Trend $p<0.001$ \\
non- $M S(\leq 2)$ & 3,018 & 84.0 & $4.31(4.22-4.39)$ & $5,912(5,867-5,958)$ \\
$M S(\geq 3)$ & 576 & 16.0 & $7.46(7.17-7.85)$ & $6,338(6,232-6,444)$ \\
& & & $p<0.001$ & $p<0.001$ \\
\hline
\end{tabular}

*Components of metabolic syndrome: obesity, high blood pressure, hypo-HDL-cholesterolemia, hypertriglyceridemia, and hyperglycemia.

**Data are adjusted for age, smoking status, drinking status, and medical histories of stroke, myocardial infarction, cancer, liver disease, asthma, and atopy.

***The geometric mean and $95 \%$ CI computed on the log-transformed fasting insulin and converted to the original scale measurement (in parentheses) are reported.

MS, metabolic syndrome.

with the increasing number of MS components $(\mathrm{p}<0.001$ for trend).

Moreover, multiple linear regression analysis performed with the WBC count as the dependent variable, and with the values of all MS components, a medical history and logtransformed insulin as the independent variables showed that BMI, HDL-C, SBP, glucose and TG had significant and independent associations with the WBC count (Table6). The insulin concentration was not significantly related to the WBC count. Only $19.7 \%$ of the variance in the WBC count was explained by this model. Additional statistical analyses were done by excluding individuals $(n=499)$ with a medical history, but this did not alter the results.

\section{Discussion}

Our large, workplace-based sample study of middleaged Japanese men has shown a strong association between the WBC count and MS as defined in ATP III (ie, obesity, high BP, hypertriglyceridemia, hypo-HDL-cholesterolemia, and hyperglycemia) after adjusting for the effects of age, smoking, drinking and medical history associated with low-grade inflammation. Others have reported an association between the WBC count and metabolic disorders 21 In the CARDIA study, significant positive associations were found between the WBC count and the SBP and BMI, respectively, and a negative correlation was found between the WBC count and HDL-cholesterol ${ }^{22}$ In the ARIC study, significant associations were observed between the WBC count and BP, insulin concentration, TG, and uric acid, 23 respectively. Targher et al investigated the association between the WBC count and CVD risk factors, and reported that a higher WBC count was associated with the clustering of components of insulin resistance syndrome ${ }^{24}$ In a study involving 5,275 middle-aged Japanese male subjects, Nakanishi et al reported that WBC counts adjusted for age, smoking and drinking were significantly higher in obese patients and those with high BP, hypertriglyceridemia, hypercholesterolemia, hypo-HDL-cholesterolemia, glucose intolerance, or hyperuricemia than in the people without these conditions ${ }^{25}$ Similar associations were found in the present study in which MS was defined as 5 disorders according to ATP III.

In the present study, subjects whose WBC count ex-
Table 6 Standardized Regression Coefficients From the Multiple Linear Regression Analysis of WBC Count in Relation to the Indicated Variables

\begin{tabular}{lcc}
\hline \hline Independent variables* & $\begin{array}{c}\text { Standardized } \\
\text { coefficients }\end{array}$ & p value \\
\hline Age & 0.03 & 0.081 \\
Body mass index & 0.05 & 0.012 \\
Systolic blood pressure & 0.05 & 0.006 \\
HDL-cholesterol & -0.10 & $<0.001$ \\
Log-transformed triglyceride & 0.11 & $<0.001$ \\
Fasting plasma glucose & 0.04 & 0.011 \\
Log-transformed fasting insulin & 0.02 & 0.373
\end{tabular}

*Independent variables: smoking status, drinking status, medical history of stroke, myocardial infarction, cancer, liver disease, asthma, and atopy were also included in addition to items in the Table.

ceeded 10,000 cells $\mu 1$, a clinically important cutoff point, were excluded. Thus, only subjects whose WBC count was within the normal range were examined. Unlike other studies, we adjusted not only for age, smoking and drinking status, but also for a previous medical history of a disease associated with low-grade inflammation. Previous studies have mainly focused on associations between the WBC count and a single metabolic disorder such as diabetes, ${ }^{26}$ hypertension ${ }^{27,28}$ or hyperlipidemia ${ }^{29}$ but it may also be associated with several of these disorders, so we investigated possible associations between the WBC count and clusters of the 5 components of MS as defined in ATP III. We found that the average WBC count became significantly higher as the number of MS components increased, which suggests that subjects with a single MS component have low-grade inflammation, which intensifies as the number of MS components increases.

Although the mechanism by which the WBC count is directly affected by each of the MS components remains unclear, there are several explanations. Vascular endothelial cells are activated by the presence of atherosclerotic risk factors, such as hypertension, hyperlipidemia and hyperglycemia. Endothelial cells produce intracellular adhesion molecule-1, an adhesion molecule, that causes WBCs to adhere to the vascular wall, after which they can penetrate the vascular endothelium and produce new cytokines and chemokines. Cytokines then activate the 
WBCs and cells comprising the vascular wall, promoting platelet aggregation and thrombus formation 30 Because proinflammatory cytokines such as tumor necrosis factoralpha (TNFa) and interleukin-6 (IL-6) have been observed in atherosclerotic plaque, ${ }^{31}$ inflammation of the vascular wall is considered to play an important role in the onset and progress of atherosclerosis. Proinflammatory cytokines are also known to increase the WBC count 32 Therefore, we surmise that the count reflects the severity of the inflammation in atherosclerotic lesions, or the severity of atherosclerosis, and that an increase in the WBC count would further exacerbate the inflammation. It has been reported that TNFa and IL-6, which elevate the WBC count, are released from adipose cells and hence are in higher concentrations in obese people 33,34 In the present investigation, we found a significantly higher WBC count in the obese compared with non-obese subjects.

We also found a significant rise in the insulin concentration, as well as in the WBC count, in relation to the increased number of MS components. However, multiple linear regression analysis of the WBC counts while simultaneously treating the MS components and the insulin concentration as the independent variables did not show any significant association between insulin concentration and the WBC count. This result suggests that insulin or insulin resistance does not directly increase the WBC count. When the positive relationships between insulin concentrations and MS components shown in Tables 3 and 5 are considered, it is more likely that insulin resistance plays an important role in the genesis of MS and because MS most likely initiates atherosclerosis, 35 it indirectly causes an increase in the WBC count as the atherosclerosis progresses. However, it is possible that MS may directly cause the increase in the WBC count through obesity or by other unknown mechanisms.

We have already reported a positive association of CRP with the clustering of metabolic disorders defined slightly different from those for MS by ATP III? In that study, compared with men who had no components of MS, those who had 1, 2, 3, 4 and 5 or more components were, respectively, $1.48,1.84,1.92,3.42$, and 4.17 times more likely to have elevated CRP concentration (CRP $\geq 0.06 \mathrm{mg} / \mathrm{dl}$ ). Together with those results, the present findings strongly suggests that inflammation underlies the development of MS. According to recent studies, 36,37 oxidative stress is a potent factors linking metabolic disorders, WBC count, and CRP. Because the multiple linear regression analysis model we used in the present study explained only $19.7 \%$ of the variance in the WBC count, it is possible that many other factors play a role in the increase in the WBC count. Further studies are necessary to elucidate the roles of WBC and $\mathrm{CRP}$ in the mechanism underlying MS and atherosclerosis.

\section{Study Limitations}

First, although waist circumference is used as the indicator for obesity in the ATP III criteria, those data were not available for the present study. Besides, the criteria for obesity in ATP III may not be suitable for Japanese who are leaner than their Western counterparts. From a study of 1,193 Japanese men, the Japan Society for the Study of Obesity reported that correlation coefficients with visceral fat measured by computed tomography were similar when BMI replaced waist circumference! 7 We therefore concluded that the obesity standard of BMI $\geq 25 \mathrm{~kg} / \mathrm{m}^{2}$ determined by the Japan Society for the Study of Obesity reflects abdominal obesity in Japanese. Second, the present study was a cross-sectional design, so it was not possible to confirm a cause and effect relationship between the increase in the WBC count and the presence of MS components or atherosclerosis. Third, our study investigated the possible association of the WBC count with insulin concentration, but not with insulin resistance. Fourth, the subjects in the present study were Japanese men, and the findings may not be applicable to women or other races with different physical characteristics. Finally, we did not have data on the fractions of the WBC. Two previous studies have shown that reactive oxygen species formation by polymorphonuclear cells (PMNs) is related to hemoglobinA1c, but not to blood glucose 36,37 One was a hospitalbased study and the mean age of the subjects was greater than 60 years ${ }^{36}$ the other included a limited number of subjects: 18 diabetic patients and 16 healthy controls? ${ }^{37}$ In the present study we observed a positive association of WBC count with serum glucose concentration among 3,594 apparently healthy men with a mean age of 50.4 years. When the finding that glucose alone modulates PMN activity ${ }^{38}$ is taken into consideration, the inconsistency between the results of previous studies and ours may be related to the differences in the subjects or other unknown factors. Further studies on the association between glucose, HbA1c, and PMNs among healthy subjects are needed.

In summary, the WBC count within the normal range showed a significant and independent association with MS itself and its 5 components (ie, obesity, high blood pressure, hypertriglyceridemia, hypo-HDL-cholesterolemia, and hyperglycemia) as defined in ATP III, but not with the insulin concentration itself. The WBC count increased as the number of MS components increased. These results suggest that there is low-grade inflammation that progresses as the MS components become clustered. In the future, biological and epidemiological research on the association among WBC, MS and CVD is required to elucidate the mechanism of the WBC count increase and to establish its cutoff point as a prognostic indicator for CVD.

\section{Acknowledgments}

We are grateful to Dr Noboru Okamoto (Aich San-no-maru Hospital), Dr Tsutomu Yoshida (Department of Public Health, Fujita Health University School of Medicine), Dr Takashi Kawamura (Kyoto University Center for Student Health), and Dr Junji Toyama (Aichi Prefectural Owari Hospital) for their cooperation in conducting the survey and collecting information for this study.

This work is supported in part by grants to Hideaki Toyoshima (09470112), Koji Tamakoshi (12670352), and Hiroshi Yatsuya (13770192) from the Ministry of Education, Culture, Sports, and Science and Technology and Japan Atherosclerosis Prevention Fund (JAPF).

\section{References}

1. Koenig W, Sund M, Frohlich M, Fischer HG, Lowel H, Doring A, et al. C-reactive protein, a sensitive marker of inflammation, predicts future risk of coronary heart disease in initially healthy middle-aged men: Results from the MONICA (Monitoring Trends and Determinants in Cardiovascular Disease) Augsburg Cohort Study, 1984 to 1992. Circulation 1999; 99: 237-242.

2. Tamakoshi K, Yatsuya H, Kondo T, Hori Y, Ishikawa M, Zhang H, et al. The metabolic syndrome is associated with elevated circulating C-reactive protein in healthy reference range, a systemic low-grade inflammatory state. Int J Obes Relat Metab Disord 2003; 27: 443 449.

3. Ichihara Y, Ohno J, Suzuki M, Anno T, Sugino M, Nagata K. Higher C-reactive protein concentration and white blood cell count in subjects with more coronary risk factors and/or lower physical fitness among apparently healthy Japanese. Circ J 2002; 66: 677-684.

4. Yarnell JW, Baker IA, Sweetnam PM, Bainton D, O'Brien JR, 
Whitehead PJ, et al. Fibrinogen, viscosity, and white blood cell count are major risk factors for ischemic heart disease: The Caerphilly and Speedwell collaborative heart disease studies. Circulation 1991; 83: 836-844.

5. Pearson TA, Mensah GA, Alexander RW, Anderson JL, Cannon RO 3rd, Criqui M, et al. Markers of inflammation and cardiovascular disease: Application to clinical and public health practice: A statement for healthcare professionals from the Centers for Disease Control and Prevention and the American Heart Association. Circulation 2003; 107: 499-511.

6. Choi H, Cho DH, Shin HH, Park JB. Association of high sensitivity C-reactive protein with coronary heart disease prediction, but not with carotid atherosclerosis, in patients with hypertension. Circ J 2004; 68: 297-303.

7. Kostis JB, Turkevich D, Sharp J. Association between leukocyte count and the presence and extent of coronary atherosclerosis as determined by coronary arteriography. Am J Cardiol 1984; 53: $997-$ 999.

8. Friedman GD, Klatsky AL, Siegelaub AB. The leukocyte count as a predictor of myocardial infarction. N Engl J Med 1974; 290: $1275-$ 1278.

9. Kannel WB, Anderson K, Wilson PW. White blood cell count and cardiovascular disease: Insights from the Framingham Study. JAMA 1992; 267: 1253-1256.

10. Weijenberg MP, Feskens EJ, Kromhout D. White blood cell count and the risk of coronary heart disease and all-cause mortality in elderly men. Arterioscler Thromb Vasc Biol 1996; 16: 499-503.

11. Brown DW, Giles WH, Croft JB. White blood cell count: An independent predictor of coronary heart disease mortality among a national cohort. J Clin Epidemiol 2001; 54: 316-322.

12. Lee CD, Folsom AR, Nieto FJ, Chambless LE, Shahar E, Wolfe DA. White blood cell count and incidence of coronary heart disease and ischemic stroke and mortality from cardiovascular disease in African-American and white men and women: Atherosclerosis risk in communities study. Am J Epidemiol 2001; 154: 758-764.

13. Sabatine MS, Morrow DA, Cannon CP, Murphy SA, Demopoulos LA, DiBattiste PM, et al. Relationship between baseline white blood cell count and degree of coronary artery disease and mortality in patients with acute coronary syndromes: A TACTICS-TIMI 18 (Treat Angina with Aggrastat and determine Cost of Therapy with an Invasive or Conservative Strategy-Thrombolysis in Myocardial Infarction 18 trial) substudy. J Am Coll Cardiol 2002; 40: 1761-1768.

14. Ferrannini E, Haffner SM, Mitchell BD, Stern MP. Hyperinsulinaemia: The key feature of a cardiovascular and metabolic syndrome. Diabetologia 1991; 34: 416-422.

15. DeFronzo RA, Ferrannini E. Insulin resistance: A multifaceted syndrome responsible for NIDDM, obesity, hypertension, dyslipidemia, and atherosclerotic cardiovascular disease. Diabetes Care 1991; 14: 173-194.

16. Gray RS, Fabsitz RR, Cowan LD, Lee ET, Howard BV, Savage PJ. Risk factor clustering in the insulin resistance syndrome: The Strong Heart Study. Am J Epidemiol 1998; 148: 869-878.

17. Ford ES. The metabolic syndrome and C-reactive protein, fibrinogen, and leukocyte count: Findings from the Third National Health and Nutrition Examination Survey. Atherosclerosis 2003; 168: 351-358.

18. Expert Panel on Detection, Evaluation, and Treatment of High Blood Cholesterol in Adults. Executive Summary of The Third Report of The National Cholesterol Education Program (NCEP) Expert Panel on Detection, Evaluation, and Treatment of High Blood Cholesterol In Adults (Adult Treatment Panel III). JAMA 2001; 285: 2486-2497.

19. Examination Committee of Criteria for 'Obesity Disease' in Japan;
Japan Society for the Study of Obesity. New criteria for 'obesity disease' in Japan. Circ J 2002; 66: 987-992.

20. SPSS Incorporated. 2001 SPSS Base 11.0J User' Guide. Chicago, IL: SPSS Inc, 2001.

21. Hansen LK, Grimm RH Jr, Neaton JD. The relationship of white blood cell count to other cardiovascular risk factors. Int J Epidemiol 1990; 19: 881-888.

22. Friedman GD, Tekawa I, Grimm RH, Manolio T, Shannon SG, Sidney S. The leukocyte count: Correlates and relationship to coronary risk factors: The CARDIA Study. Int J Epidemiol 1990; 19: $889-893$.

23. Nieto FJ, Szklo M, Folsom AR, Rock R, Mercuri M. Leukocyte count correlates in middle-aged adults: The Atherosclerosis Risk in Communities (ARIC) Study. Am J Epidemiol 1992; 136: 525-537.

24. Targher G, Seidell JC, Tonoli M, Muggeo M, De Sandre G, Cigolini M. The white blood cell count: Its relationship to plasma insulin and other cardiovascular risk factors in healthy male individuals. J Intern Med 1996; 239: 435-441.

25. Nakanishi N, Suzuki K, Tatara K. White blood cell count and clustered features of metabolic syndrome in Japanese male office workers. Occup Med (Lond) 2002; 52: 213-218.

26. Schmidt MI, Duncan BB, Sharrett AR, Lindberg G, Savage PJ, Offenbacher S. Markers of inflammation and prediction of diabetes mellitus in adults (Atherosclerosis Risk in Communities Study): A cohort study. Lancet 1999; 353: 1649-1652.

27. Friedman GD, Selby JV, Quesenberry CP Jr. The leukocyte count: A predictor of hypertension. J Clin Epidemiol 1990; 43: 907-911.

28. Nakanishi N, Sato M, Shirai K, Suzuki K, Tatara K. White blood cell count as a risk factor for hypertension: A study of Japanese male office workers. J Hypertens 2002; 20: 851-857.

29. Huang ZS, Chien KL, Yang CY, Tsai KS, Wang CH. Peripheral differential leukocyte counts in humans vary with hyperlipidemia, smoking, and body mass index. Lipids 2001; 36: 237-245.

30. Ross R. Atherosclerosis: An inflammatory diesase. $N$ Engl J Med 1999; 340: $115-126$.

31. Hansson GK. Immune and inflammatory mechanisms in the development of atherosclerosis. Br Heart J 1993; 69: S38-S41.

32. Sim E. Humoral factors. Oxford: IRL Press, 1993.

33. Hotamisligil GS, Arner P, Caro JF, Atkinson RL, Spiegelman BM. Increased adipose tissue expression of tumor necrosis factor-alpha in human obesity and insulin resistance. J Clin Invest 1995; 95: 2409 2415.

34. Mohamed-Ali V, Goodrick S, Rawesh A, Katz DR, Miles JM, Yudkin JS, et al. Subcutaneous adipose tissue releases interleukin-6, but not tumor necrosis factor-alpha, in vivo. J Clin Endocrinol Metab 1997; 82: 4196-4200.

35. Solymoss BC, Bourassa MG, Campeau L, Sniderman A, Marcil M, Lesperance J, et al. Effect of increasing metabolic syndrome score on atherosclerotic risk profile and coronary artery disease angiographic severity. Am J Cardiol 2004; 93: 159-164.

36. Yasunari K, Maeda K, Nakamura M, Yoshikawa J. Oxidative stress in leukocytes is a possible link between blood pressure, blood glucose, and C-reactive protein. Hypertension 2002; 39: 777-780.

37. Shurtz-Swirski R, Sela S, Herskovits AT, Shasha SM, Shapiro G, Nasser L, et al. Involvement of peripheral polymorphonuclear leukocytes in oxidative stress and inflammation in type 2 diabetic patients. Diabetes Care 2001; 24: 104-110.

38. Nielson CP, Hindson DA. Inhibition of polymorphonuclear leukocyte respiratory burst by elevated glucose concentrations in vitro. Diabetes 1989; 38: 1031-1035. 